\title{
Evaluating the English language scientific writing skills of Saudi dental students at entry level
}

\author{
M. El Tantawi, ${ }^{1}$ A. Al-Ansari, ${ }^{1}$ S. Sadaf ${ }^{2}$ and J. AlHumaid ${ }^{1}$
}

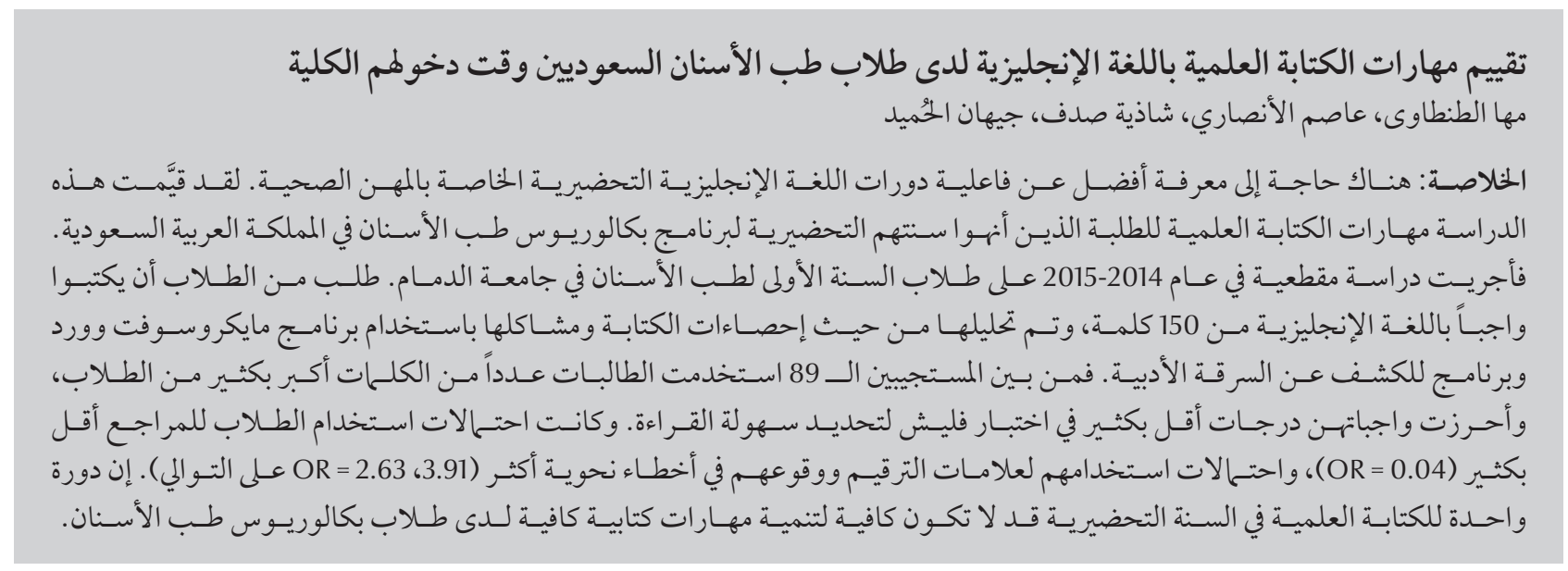

ABSTRACT Better knowledge is needed about the effectiveness of preparatory English language courses for the health professions. This study evaluated the scientific writing skills of students finishing their preparatory year of a bachelor of dentistry programme in Saudi Arabia. A cross-sectional study was conducted in 2014-15 among first-year dental students at the University of Dammam. Students were asked to write a 150-word English language assignment that was analysed for writing statistics and problems using Microsoft Word and plagiarism detection software. Of the 89 respondents, female students used a significantly greater number of words than did male students and their assignments had significantly lower Flesch reading ease scores. Male students had significantly lower odds of using references (OR 0.04) and higher odds of making punctuation and grammar mistakes (OR 2.63 and 3.91 respectively). One course of scientific writing in the preparatory year may not be enough to develop adequate writing skills among undergraduate dental students.

Évaluation des compétences en rédaction scientifique en langue anglaise des étudiants à leur entrée en médecine dentaire en Arabie saoudite

RÉSUMÉ Une meilleure connaissance des cours de préparation en langue anglaise destinés aux professions de santé est nécessaire. La présente étude a évalué les compétences rédactionnelles scientifiques des étudiants en fin d'année préparatoire du programme d'études dentaires en Arabie saoudite. Une étude transversale a été conduite entre 2014 et 2015 auprès d'étudiants en première année de médecine dentaire à l'Université de Dammam. Il a été demandé aux étudiants de rédiger un devoir de 150 mots en langue anglaise qui a ensuite été analysé pour établir des statistiques et répertorier des problèmes de rédaction à l'aide du logiciel Word de Microsoft et d'un logiciel de détection de plagiat. Sur les 89 entretiens, les étudiantes interrogées utilisaient une plus grande variété de mots que les étudiants et leur devoir présentait une mesure de lisibilité de Flesch nettement inférieure. Le nombre de références utilisées par les étudiants de sexe masculins était nettement inférieur (OR 0,04) tandis que le nombre d'erreurs de ponctuation et de grammaire était supérieur (OR 2,63 et 3,91 respectivement). Un cours de rédaction scientifique pendant l'année préparatoire semble insuffisant pour développer des compétences rédactionnelles suffisantes chez les étudiants en premier cycle de médecine dentaire. 


\section{Introduction}

Education in the health professions aims to provide students with the background knowledge, skills and values to enable them to start independent professional practice (1). This includes generic skills and attributes so that instructors can prepare graduates for their future practice. One of these skills is the ability to communicate in writing (2), an "essential skill for the many" (3). Scientific writing is a skill that is related to the general writing ability of the individual but needs to be further developed in relation to the specific field of study (4). Modern dental education standards use writing to develop and assess critical thinking, problem solving and self-assessment in addition to demonstrating a grasp of knowledge of specialty subjects (1). Writing improves understanding and recall of information and makes the application of concepts to professional practice easier (5).

Students in dental programmes usually have the greatest difficulty in demonstrating acceptable competency in scientific writing during the first year of their studies. On the one hand, they are starting to get acquainted with the principles of scientific writing for dentistry. On the other hand, they are required to submit well-structured written assignments that adequately cover the scientific aspects while using proper writing style (6). Several studies have reported the use of courses and activities to develop scientific writing skills in undergraduate students (4,5,7-10).

Achieving competence in English language scientific writing may be further complicated if English is not the first language of the students (11). In Saudi Arabia - like many other Arab countries - students seeking admission to professional programmes first join preparatory studies that include English language courses. These courses are intended to boost the students' confidence in their use of English with varying levels of emphasis on scientific terms. It is not known if these preparatory courses, in addition to the skills previously acquired during high school, help students to acquire the writing skills needed for dental programmes. Studies addressing the level of competence of dental students following introductory English language course are needed to allow better planning of dental curricula. Assessing the adequacy of this type of course and identifying the areas of deficiency will help in the development of more advanced courses tailored to the needs of students.

The present study evaluated the English language scientific writing skill of Saudi Arabian dental students at entry level, and compared male and female students regarding various aspects of the skill, after a basic English language course they received in the preparatory year before joining the programme.

\section{Methods}

\section{Study setting and sampling}

The present study was conducted in the College of Dentistry, University of Dammam, Saudi Arabia at the beginning of the academic year 2014-2015 in compliance with the principles of the Helsinki Declaration. Approval for the study was obtained from the vice deanship for academic affairs and from the research unit of the college (EA201415).

The Bachelor of Dental Sciences programme in the college extends over 5 years and is preceded by a year of preparatory studies that all students joining the health professions track have to pass. The programme has been in operation for 10 years, with male students enrolled in classes of 20-30 students on average. In 2012-2013, the first group of female students was enrolled so that at the present time segregated male and female classes exist in the first, second and third years of the programme.

The study included all dental students enrolled in the first year of the programme during the study period. These students have already passed the English language courses provided during their preparatory studies. There is a General English course of 7 credits which extends over the entire year and another course of English for Specific Purposes (for scientific terms) of 3 credits which is offered in the 2 nd semester only. In the two courses, students train to improve their language skills through reading scientific essays, composing written texts, listening to videos of native English speakers talking, making presentations, participating in discussions and answering questions about vocabulary.

\section{Data collection}

Students were asked to write a 150-word assignment in English describing why anyone would like to be a dentist. No specific instructions were given about whether they should use American or British English. They were informed that the assignment will not be graded but that it was mandatory for all students to submit it within 1 week. They were further instructed to submit the assignment as a Microsoft (MS) Word file on the college learning management system Blackboard .

All assignments were assessed as follows.

The number of words and paragraphs in the assignment was determined using the spelling and grammar checking tool in the MS Word program.

Flesch reading ease score and Flesch-Kincaid grade level score were calculated using the readability statistics tool in MS Word. The two instruments use sentence length, number of sentences in a block of text, average number of syllables per word and number of words per sentence. The reading ease score has a scale from 1 (very difficult to understand) to 100 (very easy to understand). The grade level score indicates the United States' grade school level at which the text is written. If the score is 10 , this means that the text can 
be understood by a 10th grader, i.e. a teenager 16 years old on average. The score has a ceiling effect and cannot detect a grade level higher than grade $12(12,13)$

Spelling, grammar and punctuation mistakes were assessed using the spelling and grammar checking tool in MS Word. In cases when the spelling checker indicated that a mistake was present because a word did not conform to American or British spelling, this was ignored since the aim was to assess indisputable mistakes. These were dichotomized into 0 (absence of spelling, grammar or punctuation mistakes) and $>0$ (presence of each of these mistakes).

The percentage of plagiarized content was detected by the SafeAssign software program through Blackboard. This was further dichotomized into $0 \%$ similarity (no plagiarism detected) and $>0 \%$ similarity (plagiarism detected).

The presence of references to support information in the assignment was dichotomized into 0 (no references used) and $>0$ (references used).

\section{Data analysis}

Descriptive statistics were calculated as frequencies and percentages or means and standard deviations (SD) for qualitative and quantitative variables. Means were compared between male and female students using Student $t$-test after the normality of the variables was checked using Kolmogrov-Smirnov test. Differences between male and female students in the frequency of problems in students' writing were assessed using the chi-squared test. Odds ratios (OR) and confidence intervals (CI) for the presence of various writing problems were calculated for male versus female students. The association between plagiarism and use of references was assessed using the chi-squared test. The difference in the mean number of words used by students with various types of writing problems was assessed using Student $t$-test. Correlations of number of words, reading ease score and grade level score were assessed using Pearson correlation coefficient.

\section{Results}

A total of 44 male and 45 female students submitted their assignments, with a response rate of $93.6 \%$ and $100 \%$ respectively. The overall response rate was $96.7 \%$.

Table 1 shows some of the writing statistics for the students included in the present study. Female students used significantly more words than did male students [mean number of words 296.6 (SD 39.7) and 226.5 (SD 46.9) respectively, $P<0.001]$. On average, the students divided the assignment into 4 paragraphs, with no significant difference between the sexes $(P=0.55)$. The writing of male and female students could be understood on average by a 10th grader, with female students' writing requiring a slightly higher grade than males [mean scores 10.2 (SD 2.0) versus 9.4 (SD 2.4)], although the difference between the sexes was not statistically significant $(P$ $=0.07)$. Male students' writing had a significantly higher Flesch reading ease score than did female students [mean scores 63.2 (SD 9.1) versus 55.9 (SD 8.2), $P<0.001]$.

Figure 1 shows some of the problems in students' writing. The most frequent was plagiarism ( $87 \%$ of students), followed by not using references $(80 \%)$, punctuation mistakes (52\%), grammar mistakes (45\%) and spelling mistakes (9\%). Statistically significant differences existed between male and female students in the non-use of references $(P<0.001)$ and in punctuation and grammar mistakes $(P=0.03$ and 0.002 respectively). Male students had significantly lower odds of using references (OR 0.04; 95\% CI: 0.01-0.30) and a significantly higher odds of making punctuation mistakes (OR 2.63; 95\% CI: 1.12-6.18) and grammar mistakes (OR 3.91; 95\% CI: 1.61-9.48).

There was no significant association between students' use of references and use of plagiarization $(P=0.12)$. Similarly, there was no significant difference in the mean number of words between students who were involved or not in plagiarism $(P=0.22)$, making spelling mistakes ( $P=0.82)$, making grammar mistakes $(P=0.15)$ or making punctuation mistakes $(P=0.07)$. The number of words was weakly but significantly negatively correlated with reading ease score $(r=-0.28, P=0.007)$ but not significantly correlated with grade level score $(r=0.08, P=0.46)$.

\begin{tabular}{|c|c|c|c|c|}
\hline \multirow[t]{2}{*}{ Variable } & \multicolumn{3}{|c|}{ Mean (SD) values } & \multirow[t]{2}{*}{$P$-value ${ }^{a}$} \\
\hline & Males & Females & Both sexes & \\
\hline No. of words used & $226.5(46.9)$ & $296.6(39.7)$ & $261.9(55.8)$ & $<0.001$ \\
\hline No. of paragraphs used & $4.1(2.4)$ & $4.3(1.3)$ & $4.2(1.9)$ & 0.55 \\
\hline Flesch-Kincaid grade level score & $9.4(2.4)$ & $10.2(2.0)$ & $9.8(2.2)$ & 0.07 \\
\hline Flesch reading ease score & $63.2(9.1)$ & $55.9(8.2)$ & $59.5(9.4)$ & $<0.001$ \\
\hline
\end{tabular}

${ }^{a}$ Independent t-test.

$S D=$ standard deviation . 


\section{Discussion}

Students joining undergraduate programmes in dental schools in many Arab countries are required to write scientific assignments in English as soon as they start their studies. These students usually have high grades which qualify them for dental schools and they join the dental school after passing preparatory English language courses. Thus, they are assumed to be able to proceed with these assignments properly. The present study fills a gap by providing information about the ability of these students to communicate in writing in the English language. The results showed that first-year students at the College of Dentistry, University of Dammam had modest English writing skills that needed improvement, perhaps through formal courses incorporated into the programme and integrated activities added to existing courses.

Our results are relevant to Saudi Arabian students in public dental schools. However, since the top students are usually admitted to public schools, English language writing problems in private dental schools in Saudi Arabia may exist to a greater extent, although further studies would be needed to confirm this. Our findings may be extrapolated to the situation of health profession students successfully finishing the preparatory year in any of the colleges in the Saudi higher education system. In addition, international schools accepting Saudi students should be considering these results when making arrangements for language training of the students. Our results should be applied within the limitations of our study including the sample size of one student cohort and the analysis being restricted to one assignment in one course.

Development of the academic writing skills of dental students seems to be an area of dental programmes that receives less emphasis than other skills. Part of this is related to the traditional devotion to technical skills in dental education and another factor is related to the difficulty of assessing these skills in an objective and efficient method that can be performed repeatedly to monitor student progress (14). Information technology offers a solution to this problem. In the present study, all writing statistics were automatically generated either through SafeAssign in Blackboard or through MS Word. This decreased the burden on the instructors and made possible the provision of timely feedback to the students on their performance, which is an integral part of the learning process and without which little progress can occur. It also provided objective assessment that did not rely on students' self-reports or instructors' subjective impressions. These methods, however, are not entirely error free. For example, text indicated to have no spelling mistakes by the MS Word spell checker may contain words using correct spelling for the wrong meaning. Alternatively, scientific terms are highlighted for mistakes mostly because they are not in the MS Word program dictionary.

Several studies used self-reported evaluation of writing skills by health profession students who were not native English speakers. English language writing skills were perceived to be poor by Iranian health sciences students and Iranian dental students $(15,16)$. The

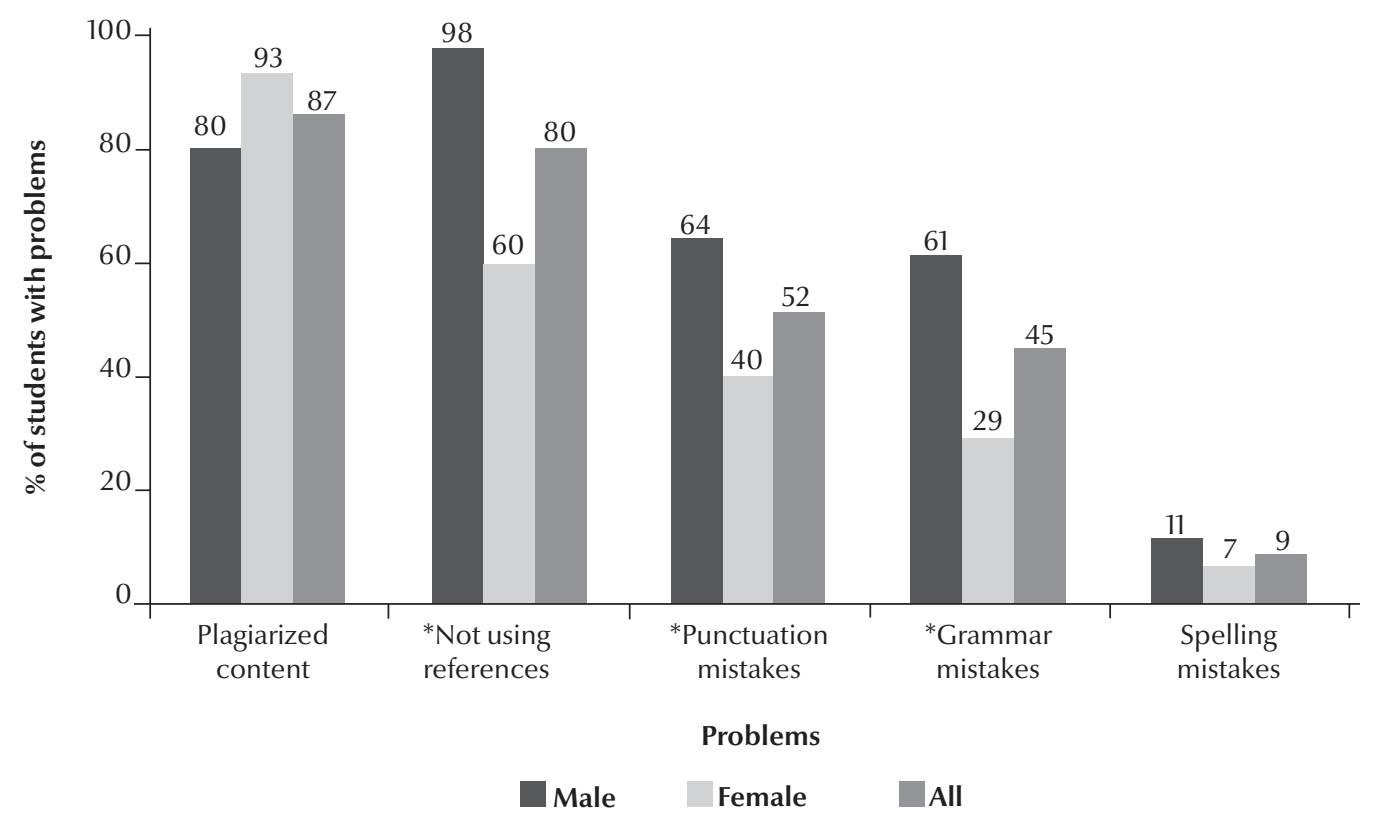

Figure 1 Problems identified in English language writing among male and female first-year dental students in University of Dammam $\left({ }^{*} \boldsymbol{P} \leq \mathbf{0 . 0 5}\right.$ male and versus females) 
same was reported by post-registration nursing students from Hong Kong who were not native English speakers (9). On an ascending scale of competence from 0 to 10 , they rated themselves a mean of 2.79/10 for the format of an academic paper, essay writing process, constructing an essay outline, plagiarism, American Psychological Association writing format and general academic writing skills. First-year medical students in the University of Adelaide significantly underestimated their writing abilities compared with their teachers. Among these students, 41\% reported English to be their second or third language. They felt they did best in using their own words (rather than reciting facts in writing from coursework) and had the least confidence in their ability to write legibly (2).

The assignments included in the present study were not graded and this was known to students beforehand. However, almost all students exceeded the word limit, with significantly more words used by female than male students. Holtzman et al. reported a similar situation in their study of 240 dental students at entry level in three successive classes (14). Most students exceeded the 250-500 word limit in the assignment they were required to submit. In some cases, students may believe that lengthier assignments get better grades. Gillet et al. evaluated the writing abilities of 45 dental students at the Bordeaux dental school (17). They found a significant correlation between the quality of writing and its quantity. The findings of the present study neither support nor refute the relation between the number of words used and the quality of writing since there was no significant difference in the number of words used between assignments without and without mistakes (grammar, spelling and punctuation). However, as the number of words increased, the reading ease score decreased, indicating more sophistication that is more likely to earn higher grades. It may be better to advise students to stick to the word limit and work on improving the quality of their writing as opposed to adding to its quantity.

The average grade level and reading ease scores of the students in this study were rather modest. Holtzman et al. in a study in New Jersey in the United States of America reported that the mean Flesch reading ease score of 240 dental students at entry level was 50.56, which is very similar to that reported in our study (score 59.5) (14). The mean Flesch-Kincaid grade level was 10.54, slightly higher than the mean in our study (score 9.8). The authors did not provide information about their students' background and the probability that English was not the mother tongue of some of their students. These results suggest that dental students in general, regardless of their language background, have common problems in academic writing. Although it might be expected that students whose first language is English would have better scientific writing skills, the comparison between our results and Holtzman et al.'s seem to indicate that the problem exists generally among dental students, regardless of their first language.

Flowerdew mentioned areas in which researchers with English as their second language have difficulty when writing in English for publication (18). Among these were grammar, use of citations and making reference to published literature. These problems are expected be even more frequent among the younger and less experienced undergraduate dental students in the present study and this was indeed the case.

In our study, there was no association between students' use of plagiarism and use of references. Omitting to cite references is recognized as one of the most frequent types of plagiarism. However, it is not the only type (19). In the present study, female students were more likely to use references although they were also more likely to plagiarize. This shows that students are not fully aware of the different types of plagiarism and that they can be involved in it even if they cite references. Practices such as copying sizeable portions of external resources with or without citation would increase the similarity detected by software such as SafeAssign. These copied portions may in part explain the slightly higher grade level score. Without the use of plagiarism detection software such as SafeAssign or Turnitin, instructors have no means of knowing if the more sophisticated writing they read is really the students' own and should therefore be rewarded or is copied from the work of others and should therefore be penalized as an act of academic dishonesty. More importantly, there is a pressing need to increase the awareness of students about what is acceptable writing and which unethical practices should be avoided. They need to be trained in the use of plagiarism detection software as soon as they are admitted into the undergraduate programme or even during the preparatory year.

In our study, male students had less sophisticated writing as shown by higher reading ease score and lower Flesch-Kincaid grade level score. They were more likely to have punctuation and grammar mistakes and less likely to cite references. Since the study was based on a single student cohort, this has to be interpreted with caution. In contrast to our findings, Holtzman et al. found no differences between male and female dental students at entry level in an American dental school regarding the number of words used to write an assignment (14). Zarshenas et al. found that male Iranian dental students rated their writing skills slightly lower than female students, although the difference between them was not statistically significant (17). Similarly, Didarloo and Khalkhali reported that the perceived level of writing did not differ between male and female Iranian health sciences students (18).

Our results need to be confirmed by studying several student cohorts including other schools and by accounting 
for performance in previous English language courses in high school and in the preparatory year. Assessing the situation among dental students in other Arab and non-native English speaking countries would help in generalizing the results on a wider scale.

\section{Conclusions}

Significantly better writing statistics were observed in the assignments submitted by female dental students, although both males and female students' writing needed improvement to avoid plagiarism, incorporate references and raise the readability level. The English language writing problems discussed in our study were similar to those reported in studies of other dental and health profession students who were native English speakers and those whose first language was neither English nor Arabic. Our study shows that one course of scientific writing in the preparatory year is not enough to develop adequate English language writing skills in undergraduate dental students. Early and continuous exposure in dental and health professions programmes to training opportunities using various teaching techniques is needed to ensure a gradual build-up of these skills. There is also a need to add greater focus on English language teaching in the pre-university education in Saudi Arabia so that students are better prepared for the challenges facing them in their university education.

\section{Acknowledgements}

Funding: None

Competing interests: None declared.

\section{References}

1. Accreditation standards for dental education programs. Chicago (IL): Commission on Dental Accreditation, American Dental Association; 2013 (http://www.ada.org/ /media/CODA/ Files/predoc.ashx, accessed 21 January 2016)

2. Chur-Hansen A. Medical students' essay-writing skills: criteriabased self and tutor-evaluation and the role of language background. Med Educ. 2000;34:194-8.

3. Projections of education statistics to 2013. Washington (DC): National Center for Education Statistics; 2003.

4. Rawson RE, Quinlan KM, Cooper BJ, Fewtrell C, Matlow JR. Writing skills development in the health professions. Teach Learn Med. 2005 Summer;17(3):233-8. PMID:16042518

5. Kolb P. Implementation of Writing Across the Curriculum (WAC) learning approaches in social work and sociology gerontology courses. Gerontol Geriatr Educ. 2013;34(2):212-23. PMID:23383857

6. Whitehead D. The academic writing experiences of a group of student nurses: a phenomenological study. J Adv Nurs. 2002;38(5):498-506. PMID:12028283

7. McMillan LR, Raines K. Headed in the "write" direction: nursing student publication and health promotion in the community.J Nurs Educ. 2010;49(7):418-21.PMID:20438030

8. Salamonson Y, Koch J, Weaver R, Everett B, Jackson D. Embedded academic writing support for nursing students with English as a second language. J Adv Nurs. 2010;66(2):413-21. PMID:20423424

9. Tarrant M, Dodgson JE, Law BVKK. A curricular approach to improve the information literacy and academic writing skills of part-time post-registration nursing students in Hong Kong. Nurse Educ Today. 2008;28:458-68. PMID:17826873
10. Tesh AS, Hyde YM, Kautz DD. A writing intensive introductory course for RN to BSN students. Nurse Educ. 2014;39(1):6-7. PMID:24300250

11. Wang M, Bakken LL. An academic writing needs assessment of English-as-a-second-language clinical investigators. J Contin Educ Health Prof. 2004;24:181-9.PMID:15490550

12. Flesch R. A readability formula that saves time. J Read. 1968;11(7):513-6.

13. Paache-Orlow MK, Taylor HA, Brancati FL. Readability standards for informed-consent forms as compared with actual readability. N Engl J Med. 2003;348(8):721-6. PMID:12594317

14. Holtzman JM, Elliot N, Biber CL, Sanders RM. Computerized assessment of dental student writing skills. J Dent Educ. 2005;69:285-95.PMID:15689614

15. Didarloo A, Khalkhali HR. Assessing study skills among university students: an Iranian survey. J Educ Eval Health Prof. 2014 May 5;11:8. PMID:24798427

16. Zarshenas L, Danaei SM, Mazarei E, Najafi HZ, Shakour M. Study skills and habits in Shiraz dental students; strengths and weaknesses. J Educ Health Promot. 2014;3:44. PMID:25013837

17. Gillet D, Quinton A, Jeannel A. Is there a link between writing ability, drawing aptitude and manual skills of dental students? Eur J Dent Educ. 2002;6:69-73.PMID:11975668

18. Flowerdew J. Writing for scholarly publication in English: the case of Hong Kong. J Second Lang Writ. 1999;8(2):123-45.

19. Turnitin.The plagiarism spectrum: instructor's insight into the 10 types of plagiarism. White paper. Oakland (CA): iParadigms LLC; 2012 (https://www2.nau.edu/d-elearn/support/tutorials/academicintegrity/pdf/Turnitin_WhitePaper_PlagiarismSpectrum.pdf, accessed 21 January 2016). 